\title{
How do free-ranging domestic herbivores reduce competition within owner-determined herds?
}

\section{Manqhai Kraai ${ }^{a, *}$, Adrian M. Shrader ${ }^{a, b}$}

${ }^{a}$ School of Life Sciences, University of KwaZulu-Natal, Private Bag X01, Scottsville, 3209, South Africa.

${ }^{b}$ Mammal Research Institute, Department of Zoology \& Entomology, University of Pretoria, Private Bag X28, Pretoria, 0028, South Africa

e-mails: kraai@ukzn.ac.za; adrian.shrader@up.ac.za

*Corresponding Author: e-mail: kraai@ukzn.ac.za; Phone: +27 33260 5506; Fax: +27 332605118

Declarations of interest: none

Word Count: 5713

\section{Highlights}

- Goats only joined patches during the wet season when feed was readily available.

- Goat herds split into subherds more frequently in the dry season.

- Interindividual distance increased in the dry season.

- Individuals in large herds reduced competition more than those in small herds. 


\begin{abstract}
Group size and competition are key drivers of foraging behaviour in social animals. With seasonal changes in food quality and availability, comes changes in the type (scramble or interference) and degree of competition (aggression or none). One way that animals can deal with these variations is by living in groups where the benefits of the group size outweigh the costs. However, this is generally not possible with domesticated animals, as group sizes are determined by owners. Thus, within these groups, animals have to make behavioural adjustments to reduce competition. To determine how domestic indigenous veld goats (Capra hircus), living in different sized owner-determined groups, dealt with seasonal variations in food availability and quality, and thus competition, we recorded their foraging behaviour. Specifically, we documented patch-joining events, herd splits, and interindividual distances (IID). We found that goats only joined the patches of other herd members during the wet season, when food was more readily available. In addition, we found that large herds split into a number of smaller subherds (comprising ca.15 individuals) that were similar in size to the unsplit small herds. Furthermore, these splits primarily happened during the dry season and were more frequent in large herds compared to small herds. Finally, IID increased in the dry season for both small and large herds, likely as a way to reduce interactions while feeding. Yet, individuals in large herds maintained larger IID than individuals in small herds, suggesting a greater attempt to reduce interactions in large herds. The fact that the large owner-determined herds had to elicit a greater number of behaviours, suggests greater levels of competition in these herds in the arid savanna system. These results suggest that by using behavioural indicators such as IID or herd splits, owners could monitor competition within their herds and determine when it would be better to keep their goats in smaller herd sizes.
\end{abstract}

Key words: goats, interindividual distances, season, herd splitting, subherds 


\section{Introduction}

One of the main benefits of group-living is increased foraging efficiency (Valone 1989;

Baciadonna et al. 2013). This happens via individuals observing the foraging of other group members and thus obtaining social information (Valone \& Templeton 2002; Shrader et al. 2007). By doing this, individuals can find food patches (local enhancement; Pöysä 1992) and assess the quality and availability of food over a wider area, quicker and more efficiently than they could on their own (Valone \& Templeton 2002; Fraser et al. 2006). Moreover, these benefits may be enhanced by group size with individuals in large groups assessing food quality and availability over a wider area than individuals in small groups (Valone 1989).

There are, however, also costs to living in groups such as competition and disease transmission (Majolo et al. 2009; Kappeler et al. 2015). By monitoring the foraging of group members and then joining them at their feeding patches (termed scrounging), individuals increase competition for food via intra-group competition (Isbell 1991; Beauchamp \& Giraldeau 1996; Sirot et al. 2012). Within these groups, competition can present itself in two forms, scramble and interference. Scramble competition occurs when an individual eats a food item, thus preventing other group members from gaining access (van Schaik \& van Noordwijk 1988; Koenig 2002). The extent of scramble competition may be influenced by group size, with larger groups experiencing greater levels (Robbins 2008). In contrast, interference competition occurs when an individual is interrupted and/or displaced by another group member before, or while feeding (Amarasekare 2002; Valeix et al. 2007; Zhang et al. 2015). If the patch-holder (producer) is chased away, then the individual joining the patch (scrounger) can monopolise the resources in the patch (King et al. 2009).

The intensity of interference, however, is likely affected by food availability (Stillman et al. 1996; Rands et al. 2006), with greater levels of aggression during periods when food is limited (Isbell 1991; Barroso et al. 2000; Fokidis et al. 2013). For herbivores, this is during the dry season when the availability and quality of vegetation declines due to utilisation and senescence (Teague 1988; OwenSmith 1994). Thus, competition for food between group-living herbivores likely increases during this critical time (Ranta et al. 1996; Wittemyer \& Getz 2007; Majolo et al. 2009). 
For wild group-living animals, group size is determined by the trade-off between the costs and benefits of group living (Roberts 1996; Kappeler et al. 2015). In contrast, domesticated animals are put into groups where group size is determined by their owners. This may be detrimental especially considering that potential costs of group size are rarely considered by livestock owners (Borries et al. 2008). When food is scarce, the benefit of staying in a group (e.g. greater foraging efficiency) may be lower than the costs (e.g. increased competition and aggression; Isvaran 2007). Thus, during these periods, it may be better for individuals to move in smaller groups. Wild, and freeranging domestic herbivores, have an advantage over herded domestic livestock, as they can change the size and structure of foraging groups in response to variation in resources (Yang et al. 2015). For example, when the availability and quality of food declines, wild herbivores can reduce competition by temporarily or permanently splitting into smaller subgroups (Smith et al. 2010). In contrast, herded livestock cannot (Estévez et al. 2007).

Within herds, one factor that influences aggression and competition between individuals is the distance they keep between themselves while foraging, termed interindividual distance (IID). When individuals forage close together, they tend to compete more, which can result in increased aggression (Estévez et al. 2007; Aschwanden et al. 2009). They can, however, reduce these costs by increasing their IIDs (van Schaik \& van Noordwijk 1988; Rands et al. 2006). For example, female kangaroos maintained greater IID in winter compared to spring due to competition for limited food (Jaremovic \& Croft 1991). As domestic livestock tend not to be able to adjust their herd sizes, adjusting IID is likely an important way in which they can reduce interference and scramble competition (Grueter et al. 2016).

The extent to which free-ranging domestic herbivores may adjust their intra-herd dynamics as a way to reduce competition and aggression is poorly understood. To explore this, we focused on the foraging interactions of free-ranging indigenous veld goats (Capra hircus) living in different sized owner-determined herds. Due to the reduction in food quality and availability during the dry season, we predicted that within these herds, 1) competition and aggressive behaviour would increase, 2) the frequency of patch-joining events would decline, 3) herds would try to reduce competition by splitting into smaller subherds, 4) the number of subherds the goats split into would increase, and 5) IID would 
increase within both unsplit herds and subherds. Moreover, we expected that these changes would be more marked in large herds (due to increased resource demand).

\section{Materials and methods}

\subsection{Study sites}

The study was conducted at three sites (Ncunjane, Jolwayo and Ngubo), around Msinga, KwaZuluNatal, South Africa ( $28^{\circ} 44^{\prime} 0^{\prime \prime}$ South, 30 27' 0" East). Jolwayo and Ngubo are located on the East and West side of the Tugela River respectively, while Ncunjane is located approximately $5 \mathrm{~km}$ West of the river. Msinga is an arid savanna landscape covered with rocky surfaces and a sparse grass layer (Fowler 2011). The region receives an annual rainfall ranging between $600-700 \mathrm{~mm}$, with the majority of the rain falling during summer (December to February) (Cousins et al. 2009). Summer temperatures range between 25 and $44{ }^{\circ} \mathrm{C}$ (Mucina \& Rutherford 2006; Cousins et al. 2009), while winter (May to July) temperatures are between -4 and $26{ }^{\circ} \mathrm{C}$ (Mucina \& Rutherford 2006). Due to limited clay soils, the area is largely unsuitable for crop farming (Fowler 2011), thus residents generally rely on livestock (goats, cattle, sheep and chickens) for their livelihoods. The landscape contains a variety of savanna tree species including deciduous Vachellia tortilis, Vachellia karroo, Vachellia nilotica, Spirostachys africana and evergreen Euclea crispa, Boscia albitrunca, and Olea europaea africana. Succulent species present include Aloe spp. and Euphorbia spp. (Mucina \& Rutherford 2006).

To determine how goats in owner-determined herds reduced competition, we collected observational data in both the wet (January and February 2015) and dry (September and October 2014) seasons from two small ( $N=12$ to 28 ; mean $=19.3 \pm 6.3$ (SD) goats) and two large ( $N=60$ to 83 ; mean $=60.4 \pm 14.8$ goats) herds at each of the three sites ( $N=12$ herds). Each herd was observed for two days, which resulted in 24 observations per season. Data were collected by two observes (a main observer and assistant) continuously scanning back and forth across the herd/subherd being observed. Despite the large number of individuals within the big herds, the small interindividual distances (IID) within these herds (see results) meant that these herds covered relatively small areas (ca. 60-180 $\mathrm{m}^{2}$ ), which facilitated data collection. As the colours and coat pattern of indigenous veld 
goats are not uniform, we were able to identify individuals via each individual's unique coat pattern and colour, body size, sex, and the presence or absence of horns. The experimental design was approved by the University of KwaZulu-Natal Animal Ethics Committee (clearance number 208/15/Animal). Moreover, no animals were adversely affected by the observations carried out during the study.

\subsection{Patch joining and aggression}

To record the degree to which goats joined the patches of other individuals while foraging, we continuously scanned back and forth across the herd and recorded all patch-joining events in the different seasons, and whether these events resulted in aggressive interactions such as head-butting and charging. To do this, we followed a single herd for two days at each site per sampling season. Observations started once the goats left their kraal (also called a corral) in the morning (at 07:45 $\mathrm{h}$ in the wet season and 07:00 $\mathrm{h}$ in the dry season) and carried on until the point when they started heading back to the kraal (at 12:15 $\mathrm{h}$ in the wet season and 15:30 $\mathrm{h}$ in the dry season). Once the goats had arrived at the feeding site, we recorded the tree species on which the joining events took place, the number, age, and sex of the goats that were feeding from the particular tree, and any aggressive interactions between the patch joiners and holders.

Upon arrival at feeding sites, the goat herds split into small subherds before feeding. To ensure that we were able to obtain data from a number of different individuals, we followed and recorded data from individuals in the largest of these subherds ( $N=3-16 \pm 3$ individuals). In addition, we determined the proportion of patch holders and patch joiners in each herd. Finally, we calculated the mean number of patch-joining events for the different herd sizes in the different seasons to determine whether these events varied with herd size.

\subsection{Herd splits}

To determine if the different sized goat herds at all three sites split into smaller subherds as a way to reduce competition while feeding, we recorded 1) if the herd split, 2) the number of subherds the herd split into, and 3) the number of individuals in each subherd. We defined a herd as being split when the 
individuals on the periphery of the potential subherds were more than $20 \mathrm{~m}$ apart. Individuals less than $20 \mathrm{~m}$ apart were considered as part of the same herd.

\subsection{Interindividual distances (IID)}

When goats arrived at a feeding site and started feeding, we estimated the IID, to the nearest metre, that individuals kept between themselves as soon as they started feeding (unsplit herd), as well as after splitting into subherds. This was done using the scan sampling method (Gilby et al. 2010), with samples taken every 10 minutes. Due to the goats being habituated to our presence, we were able to record these data while standing $5 \mathrm{~m}$ away. However, errors in the estimation of IID are more prevalent from ground observers working with large herds (Lehner 1998). In an attempt to reduce this error, we limited IID estimates to individuals that were within $10 \mathrm{~m}$ of the observers and not obstructed by other goats or vegetation. This resulted in ca. $72 \%$ and $55 \%$ of the potential IIDs being recorded in the small and large herds, respectively. We then generated a mean IID for each herd using these values, and a seasonal mean using the IID values of the herds recorded in each season (wet, dry).

\subsection{Statistical Analysis}

We used a Pearson Chi-Square $\left(\chi^{2}\right)$ test to determine if there was a difference in the number of patch-joining events in small and large herds in the wet season. We did not analyse data from the dry season, as the goats did not join the patches of other herd members during this season (see results). To determine if the number of subherds formed when a herd split (dependant variable) varied with herd size (small, large) and season (wet, dry) (independent variables), we used a 2-way ANOVA. We then used a second 2-way ANOVA to determine if the number of individuals per subherd was influenced by season (wet, dry) and/or herd size (small, large). Lastly, as we recorded data from the same herds on multiple occasions, we used a repeated measures ANOVA to determine if IID (dependent variable) was influenced by herd type (unsplit herds, subherds), unsplit herd size (small, large), and season (wet, dry) (independent variables). To determine where the significant differences 
existed in each of these ANOVAs, we ran Fisher's least significant difference (LSD) post hoc tests. We analysed all the data using SPSS version 23. Means \pm standard deviation of the mean are reported.

\subsection{Data statement}

Data have not been deposited into a public repository as the study forms part of a $\mathrm{PhD}$ that has not yet been examined. However, the corresponding author will happily provide the data upon request.

\section{Results}

\subsection{Patch joining}

For both small and large herds, patch-joining events only took place during the wet season. Yet, the number of joining events did not differ between the different sized herds (small, mean $=16.5$ \pm 3 joining events; large, mean $=27.5 \pm 5$ joining events; $\left.\chi^{2}=2, \mathrm{df}=1, \mathrm{P}=0.157\right)$. Moreover, none of the joining events resulted in aggressive interactions.

\subsection{Herd splits}

While foraging, large herds split into subherds $58 \%$ of the time during the wet season and $100 \%$ of the time during the dry season ( $N=24$ observations). Small herds showed a similar pattern ( $25 \%$ wet season, $67 \%$ dry season), but not all the small herds split into subherds during the dry season ( $\mathrm{N}=24$ observations). The number of subherds the goat herds split into was significantly influenced by season, herd size, and the interaction of season and herd size (Table 1). In both the wet and dry seasons, large herds split into more subherds when foraging, than did the small herds (Table 1). During the dry season, both small and large herds significantly increased the number of subherds in which they split into, but large herds ( $\mathrm{N}=40$ subherds) still split into more subherds than small herds ( $N=26$ subherds) (Table 1; Fig. 1). 
Table 1. Analysis of variance of the number of subherds in each herd size, number of individuals in subherds, and interindividual distances (IID) of small and large herds in the wet and dry seasons.

\begin{tabular}{lllllll}
\hline Dependent & Independent & $\begin{array}{l}\text { Sum of } \\
\text { Squares }\end{array}$ & df & Mean Squares & $\begin{array}{l}\text { F- } \\
\text { ratio }\end{array}$ & P-value \\
\hline Number of subherds & Season & 12.96 & 1 & 12.96 & 14.12 & 0.002 \\
& Herd & 17.27 & 1 & 17.27 & 21.78 & 0.004 \\
& Season*herd & 33.33 & 1 & 33.33 & 37.36 & $<0.0001$ \\
Error & & & 15 & & & \\
Individuals in subherd & Season & 133.68 & 1 & 133.68 & 12.28 & 0.001 \\
& Herd & 1306.43 & 1 & 1306.43 & 120.01 & $<0.0001$ \\
& Season*herd & 228.66 & 1 & 228.66 & 21.01 & $<0.0001$ \\
Error & & & 104 & & & \\
IID & Season & 579.30 & 1 & 579.30 & 52.72 & $<0.0001$ \\
& Herd & 475.00 & 3 & 237.50 & 17.01 & $<0.0001$ \\
& Time & 422.02 & 3 & 140.67 & 12.80 & $<0.0001$ \\
& Season*herd & 142.14 & 3 & 113.69 & 15.81 & $<0.0001$ \\
& Season*time & 106.66 & 3 & 35.55 & 3.24 & 0.024 \\
& Herd*time & 11.10 & 3 & 11.10 & 1.09 & 0.009 \\
& Season*herd*time & 96.54 & 3 & 69.50 & 10.58 & $<0.0001$ \\
& & & 182 & & & \\
\hline
\end{tabular}

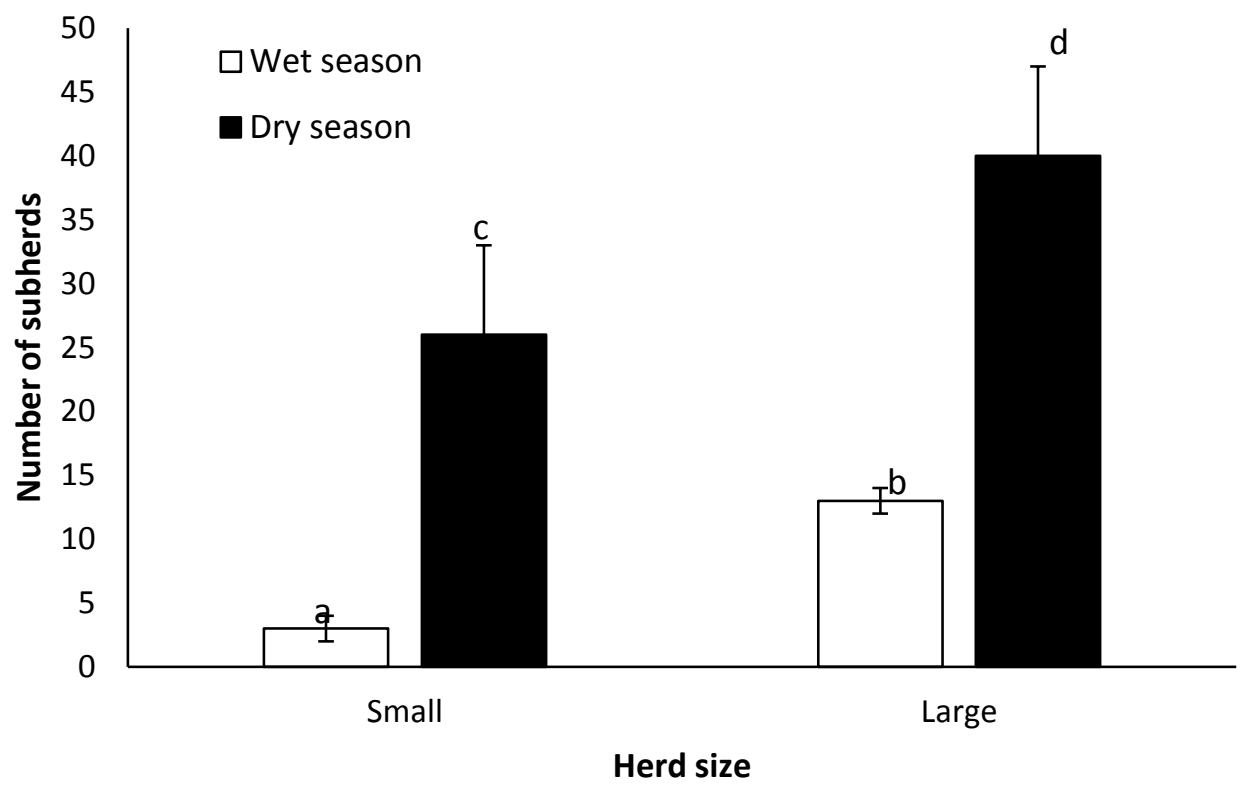

Fig. 1. Number of subherds in both small and large herds in the wet and dry seasons. Different letters indicate significant differences $(\mathrm{P}<0.001)$. 
Once split, the number of individuals in the subherds differed significantly in relation to season, the size of the unsplit herd (small, large), and the interaction of season and herd size (Table 1). Small herds that split (N=18-21 individuals) tended to divide into 3 subherds of ca. 4 individuals in both the wet $(3.0 \pm 3.6$ individuals $)$ and dry $(3.9 \pm 3.6$ individuals $)$ seasons. In contrast, in the wet season, large herds split into four subherds $(\mathrm{N}=14.6 \pm 3.1$ individuals $)$ that were similar in size to the unsplit small herds ( $\mathrm{N}=19.5 \pm 5.8$ individuals $)$. In the dry season, large herds split into smaller subherds of ca. 9 individuals $(8.6 \pm 2.9)$. This resulted in a significant drop in the number of individuals within the subherds of the large herds from the wet to dry season (Table 1; Fig. 2).

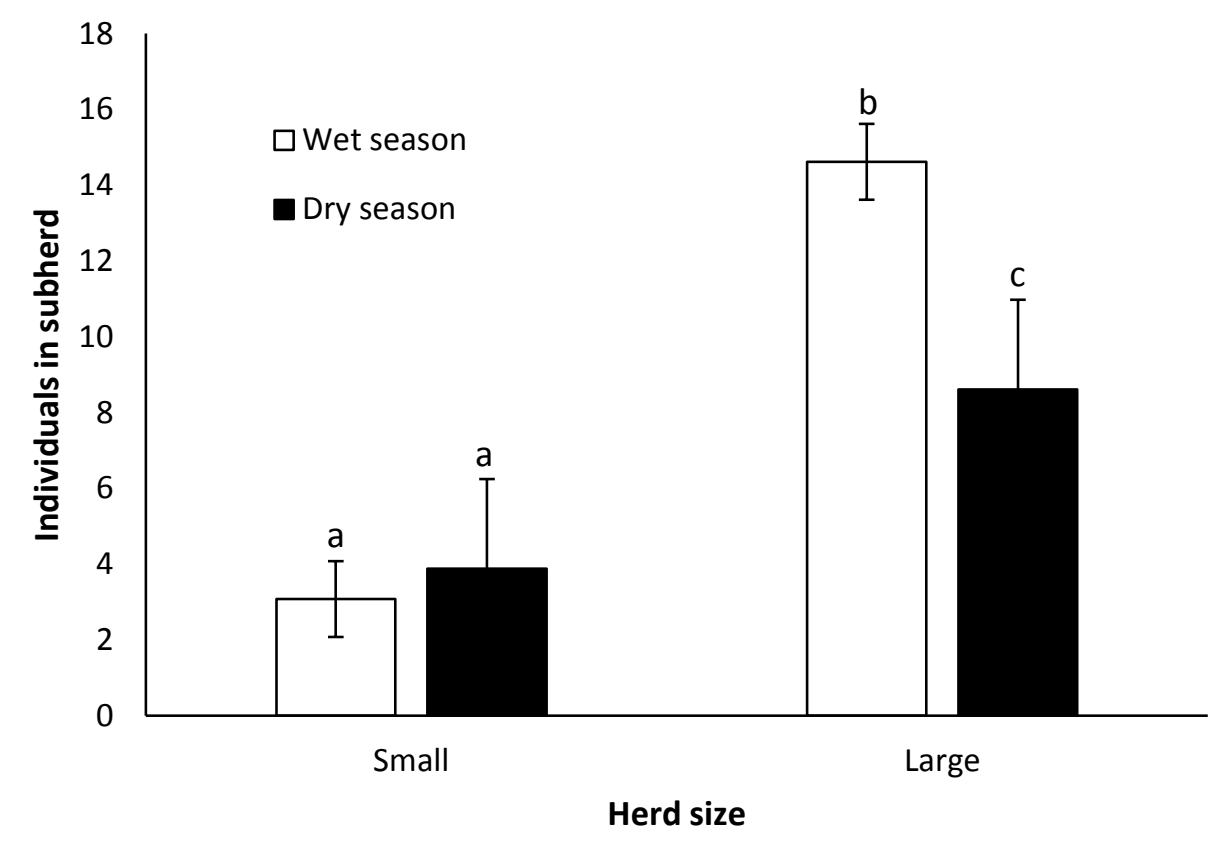

Fig. 2. Number of individuals in the subherds of both small and large herds in the wet and dry seasons. Different letters indicate significant differences $(\mathrm{P}<0.001)$.

\subsection{Interindividual distance (IID)}

The IID of the goats differed with herd type (unsplit herd, subherd), herd size, season, and the interaction of these variables (Table 1). The IID maintained by individuals in both small and large herds in both seasons differed between the unsplit herds and the resulting subherds (Table 1; Fig. 3). During the wet season, the IID before the small herds split was $1.7 \pm 1.4 \mathrm{~m}$, but then increased to 5.1 $\pm 2.2 \mathrm{~m}$ in the subherds $(\mathrm{P}=0.004)$. Likewise, the mean IID in the large herds before splitting was 1.1 
$\pm 0.9 \mathrm{~m}$ and increased to $4.4 \pm 1.8 \mathrm{~m}$ in the subherds $(\mathrm{P}=0.005)$. Similar patterns were found during the dry seasons, but the IIDs were greater. Specifically, in small herds, IID increased from $4.4 \pm 2.4$ to $7.8 \pm 4.4 \mathrm{~m}(\mathrm{P}=0.0001)$ as individuals shifted from moving in the unsplit herd to moving in subherds. Similarly, in large herds, IIDs increased from $4.5 \pm 2.2$ in the unsplit herd to $12.1 \pm 4.2 \mathrm{~m}$ $(\mathrm{P}=0.0001)$ in the subherd. Overall, the IID between individuals in the small and large herds were similar in the different seasons and herd types. The only exception was during the dry season where individuals in the subherds of the large herds maintained significantly greater IIDs compared to individuals in the subherds of the small herds (Fig. 3; $\mathrm{P}=0.0001$ ).

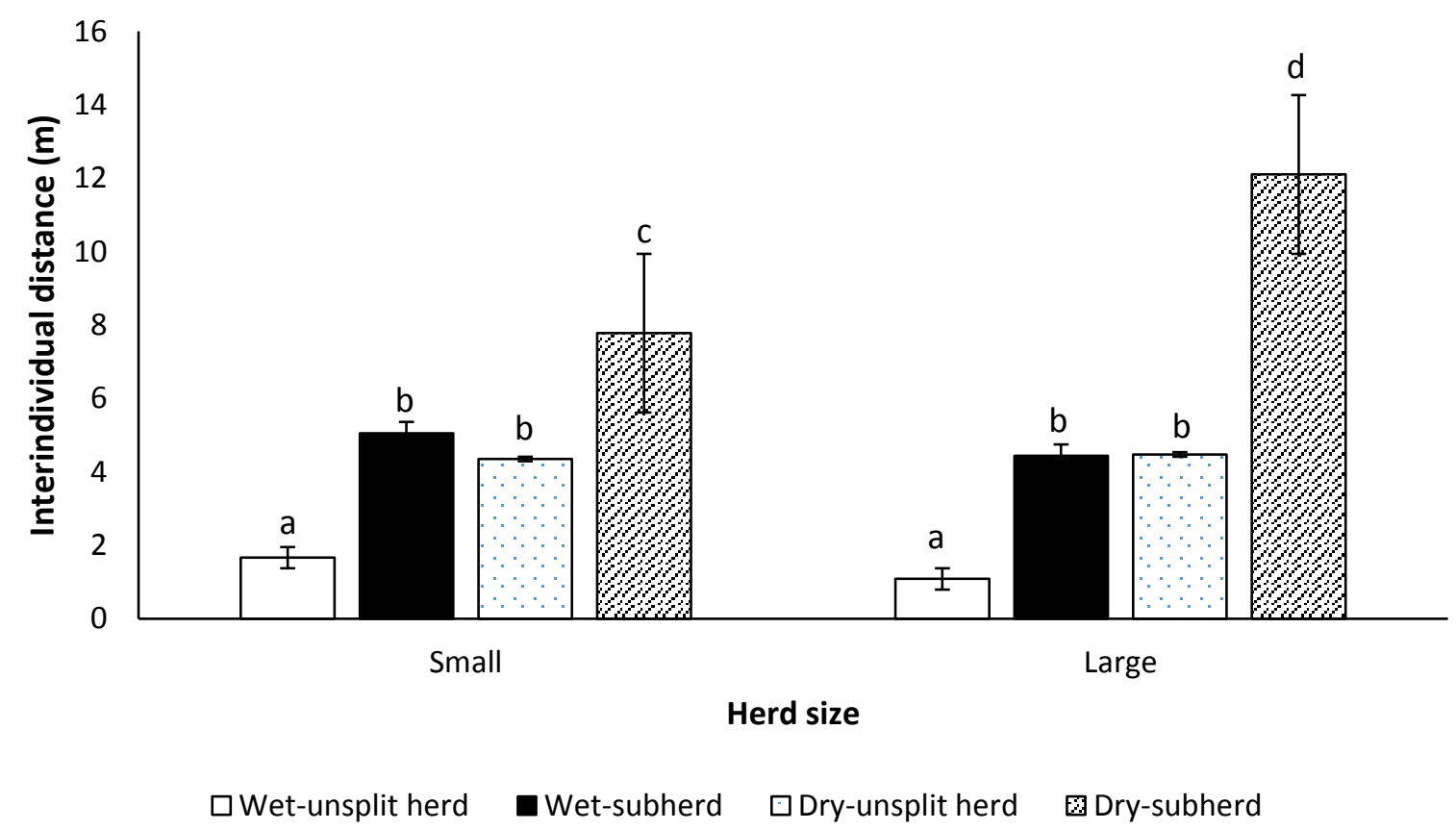

Fig. 3. Interindividual distances of unsplit and subherds of both large and small herds during the wet and dry seasons. Different letters indicate significant differences $(\mathrm{P}<0.05)$.

\section{Discussion}

For herbivores, living in groups can result in greater feeding efficiency, but also greater competition as group members join individuals at food patches (Chapman et al. 1995; Isvaran 2007). This is especially true during the dry season when food availability and quality is poor (Jaremovic \& Croft 1991; Owen-Smith 1994). Free-ranging herbivores, can reduce these costs by utilising a suite of behaviours such as adjusting herd sizes and IID within herds. However, the options available to 
domestic herbivores living in owner-determined herds may be more limited. When focussing on goats in owner-determined herds that free-ranged when feeding, we found that patch-joining events, in both large and small herds, only took place during the wet season when high quality food is readily available. Moreover, these events did not involve aggressive interactions. However, in both seasons, small and large goat herds split into smaller subherds. Yet, larger herds split more often, and interestingly when they split, they formed subherds that were similar in size to the unsplit small herds. Finally, individuals in both large and small herds maintained similar IIDs in both unsplit herds and subherds. The only exception was during the dry season, when individuals in the subherds of large herds maintained greater IIDs than individuals in the subherds of small herds.

Within groups, individuals can compete via both scramble and interference competition by individuals joining the patches of other group members (Robbins 2008; Sirot et al. 2012; Zhang et al. 2015). With declines in food availability and quality during the dry season, we expected more patchjoining events as a way of reducing search time and thus increasing foraging efficiency, especially in larger herds. This, however, did not happen. In contrast, the goats completely avoided the patches of other group members during the dry season and only joined during the wet season. A possible reason for this, is that the amount of food available in the different patches was so low that the potential food that could be obtained by a scrounging individual, after the finder's share (i.e. the amount of food eaten by the patch holder prior to other individuals joining the patch; Vickery et al. 1991) had been removed, was lower than what could be obtained by an individual searching for its own patch. For example, Kok et al. (2017) found when food availability was low (40 \& $100 \mathrm{~g}$ ), that individuals would avoid patches in which patch holders had fed for as little as 30 seconds. They suggested that this was likely due to the patch holders extensively reducing food availability, and thus patch attractiveness to potential joiners. It is possible that due to the poor-quality environment in which our study was conducted, that the goats in the different herds faced a similar situation. As a result, they did not increase competition during this time of the year by joining patches, but rather looked for their own patches in which to feed (Beauchamp \& Giraldeau 1996).

The lack of aggressive interactions and the fact that individuals were not displaced when herd members joined them at their patches during the wet season, indicates that the main form of 
competition between goats during this period was via scramble competition, and not interference competition. This suggests that the availability of food in the patches during the wet season was high enough that patch joiners did not have to chase away the patch holders to ensure that they obtained adequate intake. Yet, competition for food may result in animals adjusting their intake rates. For example, Thomas's langur (Presbytis thomasi) females were reported to increase their intake rate when the group size increased (Steenbeek \& van Schaik 2001). In addition, Shrader et al. (2007) found that goats increased their intake rates as the number of potential competitors increased. As we did not record intake rates, it may be possible that patch holders increased their intake rates when herd members joined them at their patches. If so, then this would increase the amount of food that they obtained from the patch. Yet, the lack of aggression in patch-joining events tends to suggest that even if patch holders did increase their intake rates, it was not enough to significantly reduce the potential intake of the patch joiners.

There are a number of reasons why groups may temporarily split into smaller subgroups. First, splitting may occur as a result of agonistic behaviour between group members, with the resulting subherds comprising individuals that show low levels of aggression towards each other (Gerard et al. 2002). We, however, did not record aggression between individuals in the unsplit herds, thus this is unlikely to be the main driver in this study. Second, it could be that groups split to limit competition for limited resources between group members. For example, feral goats were found to exhibit smaller group sizes in the dry season, when competition for food is highest (Shi et al. 2005). In addition, Arnold et al. (1981) found that as flock sizes increased, Dorset Horn sheep (Ovis aries) split into subgroups when foraging. Merino sheep (Ovis aries) also split into subherds, but only when food availability was low (Arnold et al. 1981).

In our study, the frequent splitting of herds into subherds, especially for large herds, in the dry season when food tends to be less abundant and of lower quality (Isvaran 2007; Yang et al. 2015), suggests that the key driver of herd splitting was increased competition between herd members. By moving in smaller herds, individuals were likely better able to locate unexploited food patches (Isvaran 2007; Morand-Ferron \& Quinn 2011). Moreover, small groups are unlikely to experience high levels of competition (Steenbeek \& van Schaik 2001). Interestingly, the large herds split into 
subherds that were similar in size to the unsplit small herds. This, coupled with the lower splitting frequency in the small herds, suggests that the owner-determined herd sizes of between 12 and 28 individuals may be better suited to the arid environment of the study site.

If splitting into smaller subherds was the first strategy that the goats used to reduce potential intra-herd competition (likely scramble competition), it was apparently not enough. This is indicated by the fact that once they were in these subherds, individuals also increased their IID. Moreover, the greatest increase in IID was during the dry season in the subherds of the large herds. By maintaining greater IIDs, especially during the dry season, group members likely reduced competition. For example, large groups of female long-tailed macaques (Macaca fascicularis) maintained large IID distances as a way to reduce competition when feeding (van Schaik \& van Noordwijk 1988). In addition, subordinate Japanese macaque (Macaca fuscata) females maintained large IID to avoid being displaced from food patches by dominant individuals (Saito 1996). Thus, it would seem that for the goats in our study, the way in which they reduced competition within the owner-determined herd sizes was to use a combination of splitting into smaller subherds, and then increasing their IIDs once in these subherds.

\section{Conclusion}

Overall, our results tend to suggest that for the goats in Msinga, the costs associated with living in the artificially determined large herds outweighed the benefits of being in these herds. As a result, it seems like these goats attempted to minimise competition once they were away from the kraal and livestock owner. They did this by splitting into small subherds when feeding, maintaining greater IIDs within these subherds, and not aggressively joining patches during the dry season when food availability and quality were likely low. In contrast, the seasonal stability of the small herds, and the lower formation of subherds tends to suggest that the cost:benefit trade-offs of group size were better for goats within the artificially determined small herds compared to the large herds. However, even the small herds divided into subherds. The results of our study suggest that livestock owners may be able to use behavioural indicators such as the frequency with which herds split into smaller subherds and/or IID as ways to monitor the degree of competition within their herds. The number of 
behavioural adjustments made by the large herds could suggest that it would be better for livestock owners to keep their goats in small herds in this arid environment, or at least allow large herds to split into smaller subherds when feeding. By doing so, livestock owners may reduce competition and aggression within their goat herds, and possibly increase animal health, weight gain, and productivity (Nogueira et al. 2016).

\section{Acknowledgements}

We thank Mdukatshani Rural Development Trust and farmers for allowing us to work with their goats. We also thank Peter F. Scogings for introducing us to goat farming in Msinga. This work was support by the University of KwaZulu-Natal, National Research Foundation (Grant: 77582 A.M.S) and National Research Foundation Thuthuka Funding Instrument (Grant: 94021).

\section{References}

Amarasekare, P., 2002. Interference competition and species coexistence. Proc. R. Soc. London, B. $269,2541-2550$.

Arnold, G.W., Wallace, S.R., Rea, W.A., 1981. Associations between individuals and home-range behaviour in natural flocks of three breeds of domestic sheep. Appl. Anim. Ethol. 7, 239-257. Aschwanden, J., Gygax, L., Wechsler, B., Keil, N.M., 2009. Structural modifications at the feeding space: effects of partitions and platforms on feeding and social behaviour of goats. Appl. Anim. Behav. Sci. 119, 180-192.

Baciadonna, L., McElligott, A.G., Briefer, E.F., 2013. Goats favour personal over social information in an experimental foraging task. PeerJ 1, e172.

Barroso, F.G., Alados, C.L., Boza, J., 2000. Social hierarchy in the domestic goat: effect on food habits and production. Appl. Anim. Behav. Sci. 69, 35-53.

Beauchamp, G., Giraldeau, L.-A., 1996. Patch exploitation in a producer-scrounger system: test of a hypothesis using flocks of spice finches (Lonchura punctulata). Behav. Ecol. 8, 54-59.

Borries, C., Larney, E., Lu, A., Ossi, K., Koeniga, A., 2008. Costs of group size: lower developmental and reproductive rates in larger groups of leaf monkeys. Behav. Ecol. 19, 1186-1194. 
Chapman, C.A., Wrangham, R.W., Chapman, L.J., 1995. Ecological constraints on group size: an analysis of spider monkey and chimpanzee subgroups. Behav. Ecol. Sociobiol. 32, 199-209.

Cousins, B., Hornby, D., Mweli, M., Alcock, R., Masondo, M., Mbatha, G., Dladla, N., 2009. The land laws of Msinga and potential impacts of the Communal Land Rights Act. Church Agricultural Projects and the Learning and Action Project.

Estévez, I., Andersen, I.L., Nævdal, E., 2007. Group size, density and social dynamics in farm animals. Appl. Anim. Behav. Sci. 103, 185-204.

Fokidis, H.B., Prior, N.H., Soma, K.K., 2013. Fasting increases aggression and differentially modulates local and systemic steroid levels in male zebra finches. Endocrinology 154, 43284339.

Fowler, K.D., 2011. The Zulu ceramic tradition in Msinga, South Africa. South. Afr. Humanities 23, 173-202.

Fraser, C.P., Ruxton, G.D., Broom, M., 2006. Public information and patch estimation for group foragers: a re-evaluation of patch-quitting strategies in a patchy environment. Oikos 112, 311321.

Gerrard, J.F., Bideau, E., Maublanc, M.L., Loisel, P., Marchal, C., 2002. Herd size in large herbivores: encoded in the Individual or emergent? Biol. Bull. 202, 275-282.

Gilby, I.C., Pokempner, A., Wrangham, R.W., 2010. A direct comparison of scan and focal sampling methods for measuring wild chimpanzee feeding behaviour. Folia Primotologica 81, 254-264.

Grueter, C.C., Robbins, A.M., Abavandimwe, D., Vecellio, V., Ndagijimana, F., Ortmann, S., Stoinski, T.S., Robbinsa, M.M., 2016. Causes, mechanisms, and consequences of contest competition among female mountain gorillas in Rwanda. Behav. Ecol. 27, 766-776.

Isbell, L.A., 1991. Contest and scramble competition: patterns of female aggression and ranging behaviour among primates. Behav. Ecol. 2, 143-155.

Isvaran, K., 2007. Intraspecific variation in group size in the blackbuck antelope: the roles of habitat structure and forage at different spatial scales. Oecologia 154, 435-444.

Jaremovic, R.V., Croft, D.B., 1991. Social organization of eastern grey kangaroos in southeastern New South Wales. II. Associations within mixed groups. Mammalia 55, 543-554. 
Kappeler, P.M., Cremer, S., Nunn, C.L., 2015. Sociality and health: impacts of sociality on disease susceptibility and transmission in animal and human societies. Philos. Trans. R. Soc. London, B 70, 1-10.

King, A.J., Isaax, N.J.B., Cowlishaw, G., 2009. Ecological, social, and reproductive factors shape producer-scrounger dynamics in baboons. Behav. Ecol. 20, 1039-1049.

Koenig, A., 2002. Competition for resources and its behavioral consequences among female primates. Inter. J. Primatol. 23, 759-783.

Kok, R.B., Stears, K., Shrader, A.M., 2017. Does the removal of finder's share influence the scrounging decisions of herbivores? Anim. Behav. 133, 229-235.

Lehner, P.N. 1996. Handbook of ethological methods, second ed. Cambridge University Press, Cambridge.

Majolo, B., Ventura, R., Koyama, N.F., Hardie, S.M., Jones, B.M., Knapp, L.A., Schino, G., 2009. Analysing the effects of group size and food competition on Japanese macaque social relationships. Behaviour 146, 113-137.

Morand-Ferron, J., Quinn, J.L., 2011. Larger groups of passerines are more efficient problem solvers in the wild. Proc. Nat. Acad. Sci. 108, 15898-158903.

Mucina, L., Rutherford, M.C., 2006. The vegetation of South Africa, Lesotho and Swaziland. South African National Biodiversity Institute, Pretoria.

Owen-Smith, N., 1994. Foraging responses of kudus to seasonal changes in food resources: elasticity in constraints. Ecology 75, 1050-1062.

Nogueira, D.M., Gummow, B., Gardiner, C.P., Cavalieri, J., Fitzpatrick, L.A., Parker, A.J., 2016. A survey of the meat goat industry in Queensland and New South Wales. 2. Herd management, reproductive performance and animal health. Anim. Prod. Sci. 56, 1533-1544.

Pöysä, H., 1992. Group Foraging in Patchy Environments: The importance of coarse-level local enhancement. Ornis Scandinavica 23, 159-166.

Rands, S., Pettifor, R.A., Rowcliffe, J.M., Cowlishaw, G., 2006. Social foraging and dominance relationships: the effects of socially mediated interference. Behav. Ecol. Sociobiol. 60, 572581. 
Ranta, E., Peuhkuri, N., Laurila, A., Rita, H., Metcalfe, N.B., 1996. Producers, scroungers and foraging group structure. Anim. Behav. 51, 171-175.

Robbins, M.M., 2008. Feeding competition and agonistic relationships among Bwindi Gorilla beringei. Int. J. Primat. 29, 999-1018.

Roberts, G., 1996. Why individual vigilance declines as group size increases. Anim. Behav. 51, 10771086.

Saito, C., 1996. Dominance and feeding success in female Japanese macaques, Macaca fuscata: effects of food patch size and inter-patch distance. Anim. Behav. 51, 967-980.

Shi, J., Dunbar, R.I.M., Buckland, D., Miller, D., 2005. Dynamics of grouping patterns and social segregation in feral goats (Capra hircus) on the Isle of Rum, NW Scotland. Mammalia 69, 185-199.

Shrader, A.M., Kerley, G.I.H., Kotler, B.P., Brown, J.S., 2007. Social information, social feeding, and competition in group-living goats (Capra hircus). Behav. Ecol. 18, 103-107.

Sirot, E., Maes, P., Gélinaud, G., 2012. Movements and conflicts in a flock of foraging black-tailed godwits (Limosa limosa): the influence of feeding rates on behavioural decisions. Ethology $118,127-134$.

Smith, L.A., Wells, K.L., Marion, G., Swain, D.L., Hutchlings, M.R., 2010. Effects of group composition on the grazing behaviour of herbivores. Anim. Behav. 80, 527-534.

Steenbeek, R., van Schaik, C.P., 2001. Competition and group size in Thomas's langurs (Presbytis thomasil: the folivore paradox revisited. Behav. Ecol. Sociobiol. 49, 100-110.

Stillman, R.A., Goss-Custard, J.D., Clarke, R.T., Dit Durell, S.E.A. Le V., 1996. Shape of the interference function in a foraging vertebrate. J. Anim. Ecol. 65, 813-824.

Teague, W.R., 1988. The response of Acacia karroo plants to defoliation by hand compared to defoliation by goats. Gras. Soc. South Africa 5, 122-124.

Valeix, M., Chamaille-Jammes, S., Fritz, H., 2007. Interference competition and temporal elephants and herbivore communities at waterholes. Oecologia 153, 739-748.

Valone, T.J., Templeton, J.J., 2002. Public information for the assessment of quality: a widespread social phenomenon. Philos. Trans. R. Soc. London, B 357, 1549-1557. 
Valone, T.J., 1989. Group foraging, public information, and patch estimation. Oikos 56, 357-363.

Van Schaik, C.P., Van Noordwijk, M.A., 1988. Scramble and contest in feeding competition among female long-tailed macaques (Macaca fascicularis). Behaviour 105, 77-98.

Vickery, W.L., Giraldeau, L.-A., Templeton, J.J., Kramer, D.L., Chapman, C.A., 1991. Producers, Scroungers, and Group Foraging. Am. Nat. 137, 847-863.

Wittemyer, G., Getz, W.M., 2007. Hierarchical dominance structure and social organization in African elephants, Loxodanta africana. Anim. Behav. 73, 671-681.

Yang, L., Zhou, L., Song, Y., 2015. The effects of food abundance and disturbance on foraging flock patterns of the wintering Hooded Crane (Grus monacha). Avian Res. 6, 1-8.

Zhang, L., Andersen, K.H., Dieckmann, U., Brännström, A., 2015. Four types of interference competition and their impacts on the ecology and evolution of size-structured populations and communities. J. Theor. Biol. 380, 280-290. 
